\title{
Changes of Mineralogical Properties and Biological Activities of Gypsum and Its Calcined Products with Different Phase Structures
}

\author{
Kaiyang Liu $\mathbb{D}^{1},{ }^{1}$ Shu Han $\mathbb{D}^{1},{ }^{1}$ Wei Gao, ${ }^{2}$ Ya'nan Tang $\mathbb{D}^{1},{ }^{1}$ Xitao Han $\mathbb{D}^{1},{ }^{1}$ Ziqin Liu $\mathbb{D}^{1}{ }^{1}$ \\ Liyuan Bao, ${ }^{1}$ Meiru Zhi $\left(\mathbb{D},{ }^{1}\right.$ Hongyue Wang ${ }^{(D,},{ }^{1}$ Yingli Wang, ${ }^{3}$ and Hong Du ${ }^{1}{ }^{1}$ \\ ${ }^{1}$ School of Chinese Materia Medica, Beijing University of Chinese Medicine, Beijing 102488, China \\ ${ }^{2}$ School of Traditional Chinese Medicine, Beijing University of Chinese Medicine, Beijing 102488, China \\ ${ }^{3}$ Shanxi University of Chinese Medicine, Jinzhong, Shanxi 030619, China
}

Correspondence should be addressed to Hong Du; duhong@vip.163.com

Received 16 December 2020; Revised 11 February 2021; Accepted 24 February 2021; Published 10 March 2021

Academic Editor: Jie Liu

Copyright (c) 2021 Kaiyang Liu et al. This is an open access article distributed under the Creative Commons Attribution License, which permits unrestricted use, distribution, and reproduction in any medium, provided the original work is properly cited.

Raw gypsum (RG) and calcined gypsum (CG) are widely used in traditional Chinese medicine (TCM). RG is usually taken orally to resolve heat and diminish inflammation, while CG is only used externally to treat ulcerations and empyrosis. Calcination at different temperatures, three phase CG structures, namely, bassanite, anhydrite III, and anhydrite II, may be generated. We herein investigated the relationship between the phase structure and the efficacy of CG and the optimum phase structure for CG. RG has a compact structure, small pore size, weak anti-inflammatory effect, but no antibacterial effect, and has almost no effect on the repair of scalds. CG150 (bassanite) has a loose texture, large pore size and specific surface area, and certain antibacterial and antiinflammatory effects, but it has a poor repair effect on scalds. CG750 (anhydrite II) has a compact structure, small pore size and specific surface area, and low antibacterial and anti-inflammatory effects, but it has a certain repair effect on scalds. Only CG350 (anhydrite III) has good performance in texture, pore size, specific surface area, antibacterial, anti-inflammatory, and scald repair. Our research has proved that the mineral properties and biological activities of CG are different due to different phase structures. CG350, namely, anhydrite III, is considered by our research to be the optimal phase structure as CG.

\section{Introduction}

Gypsum is a monoclinal crystal mineral. Its main component is $\mathrm{CaSO}_{4}-2 \mathrm{H}_{2} \mathrm{O}$ [1]. Referred to as "Shi Gao" in Chinese, it has been used as a mineral medicine in China for thousands of years. Gypsum was first recorded in China's earliest materia medica book called "Shen Nong's Classic Materia Medica" ("Han" dynasty), and it is still widely used in the clinical practice of traditional Chinese medicine in modern times.

In TCM, gypsum can be used in two forms: raw gypsum (RG) and calcined gypsum (CG) [2], which are very different in their functions and usage. RG is usually used in decoction for oral administration, treating high fever, headache, and various inflammations [3,4]. However, CG is the only medicine for external application, treating empyema, ulcers, and empyrosis [2]. According to Chinese Pharmacopeia requirements, CG should be calcined at a high temperature until it is crispy and easily crushed. However, the optimal calcination temperature for preparing CG is not specified. Studies have shown that three different phase structures, namely, bassanite, anhydrite III, or anhydrite II [5-7], will be produced when calcined at different temperatures. Previous studies only focused on changes of $\mathrm{Ca}^{2+}$ or whether the crystal water was utterly removed before and after calcination [8]. As far as we know, the changes of mineral properties of CGs with different phase structures or their antibacterial, anti-inflammatory, and scald treatment effects have never been studied hitherto.

CG is usually used to treat scald, with exudate absorption, wound healing, and muscle regeneration. According to TCM theory, CG needs to be calcined to opaque, crisp, and reddish. In the process of producing CG, colour and texture are essential appearance indexes to control product quality. 
Microstructure and pore size are often considered as mineralogical properties related to the exudate absorption ability of CG. When the scald occurs, wounds often suffer from microbial infections in untreated situations. After wounds infection, toxic molecules and metabolites produced by persistent inflammatory and bacterial and immune responses adversely affect wound repair [9]. According to related studies, E. coli, as a Gram-negative bacterium, is a relatively common strain of scald infection, which secretes toxins (exotoxins) that affect tissue repair [10]. During the inflammatory reaction stage of scald, there are often many overexpressed inflammatory factors, such as interleukin- $1 \beta$ (IL-1 $\beta$ ) and nitric oxide (NO), which inhibit wound healing [11]. So, inhibiting microbial infection and alleviating inflammation can promote wound healing. Therefore, in this study, the efficacy of CG can be comprehensively evaluated by in vitro bacteriostatic and anti-inflammatory experiments and the expression of growth factor (transforming growth factor, TGF) related to animal scald.

To clarify which phase structure is most suitable for being included in the clinical practice, we investigated the mineralogical properties and biological activities of CGs calcined at different temperatures $\left(150^{\circ} \mathrm{C}, 350^{\circ} \mathrm{C}\right.$, and $\left.750^{\circ} \mathrm{C}\right)$ and RG. Fourier transform infrared spectroscopy (FTIR) and X-ray diffraction (XRD) were used to confirm the phase structure and phase composition. Scanning electron microscopy (SEM) was applied to detect the variation of microstructure. A surface area porosity analyzer (SAPA) was used to measure the pore volume and surface area, and a colorimeter was conducted to qualify the colour. In vitro, the bacterial experiment was carried out to detect the bacteriostatic activity, and a cell experiment was implemented to detect the anti-inflammatory activity. In vivo, a scald animal model was constructed to detect the repairing effect of CGs with different phase structures on scaled skin.

\section{Materials and Methods}

2.1. Preparation of Samples. Gypsum (license number: 1903137) was purchased from Beijing Shengshilong Pharmaceutical Co., Ltd. and identified by Professor Jingjuan Wang, an expert at Beijing University of Chinese Medicine.

Preparation of RG samples: crushing GF by ultrafine pulverizer and then sieved through a 200-mesh to obtain fine powder (particle size less than $0.074 \mathrm{~mm}$ ).

Preparation of CG samples: $10 \mathrm{~g}$ of RG was put into a muffle furnace (KSW-6-12 ASP, Beijing Kewei Yongxing Instrument Co., Ltd.) and calcined at $150^{\circ} \mathrm{C}, 350^{\circ} \mathrm{C}$, and $750^{\circ} \mathrm{C}$ for 1.5 hours, respectively, to obtain CG samples named CG150, CG350, and CG750, respectively.

\subsection{Determination of Phase Structure}

2.2.1. FTIR Analysis. To reveal changes in the molecular structure of RG, CG150, CG350, and CG750, RG, CG150, CG350, and CG750 were mixed with $\mathrm{KBr}$ at the ratio of 1 : 100 and pressed into transparent sheets, respectively. FTIR spectroscopic characterization was determined using a FTIR spectrometer equipped with a DTGS detector (MB104, ABB
Bomen Co., Quebec, Canada) in the range of $4000-400 \mathrm{~cm}^{-1}$. Each spectrum was recorded at the resolution of $4 \mathrm{~cm}^{-1}$ with 64 coadded scans. Spectrum Version 5.0 software (PerkinElmer Company) was used to collect all sample data. The data were processed by OMNIC 6.0 software (Thermo Electron Corporation, Madison, WI, USA).

2.2.2. XRD Analysis. To analyze the phase composition of RG, CG150, CG350, and CG750, we detected all samples by using XRD. XRD patterns were collected on a diffractometer (Rigaku D/max 2500) with a detector voltage of $30 \mathrm{kV}$ and $30 \mathrm{~mA}$ using a $\mathrm{CuKa}$ radiation source, and the scan speed was $8^{\circ} \mathrm{min}^{-1}$ with the $2 \theta$ range of $10-80^{\circ}$.

\subsection{Mineralogical Properties Analysis}

2.3.1. SEM Observation. The samples' microstructure was observed utilizing field emission scanning electron microscopy (FESEM) (JSM-7001F, Japan). The powders of RG, CG150, CG350, and CG750 were evenly dispersed on the sample table with double-sided adhesive tape and then were sputter-coated with gold $(\mathrm{Au})$ and observed using FESEM. Measurement conditions: scanning electron microscope resolution, $2 \mathrm{~nm}(30 \mathrm{KV}) / 3.0 \mathrm{~nm}(1 \mathrm{KV})$; acceleration voltage, $20 \mathrm{KV}$.

2.3.2. Textural Properties. The nitrogen isotherms at the liquid nitrogen temperature were measured on SAPA $(3 \mathrm{H}-$ 2000, Beishide, China). The Brunauer-Emmett-Teller (BET) model [12] was used to obtain the surface area. Pore size distribution curves and average pore sizes were calculated by analyzing the adsorption branches of isotherms, based on the Barrett-Joyner-Halenda (BJH) algorithm [13].

2.3.3. Colour Quantification. The colors of RG, CG150, CG350, and CG750 sample powders were measured by a colorimeter (Konica Minolta Japan, CM-5). The colorimeter consists of a measuring head, white calibration board, black calibration board, and colour management software (SpectraMagic NX). Six random measurements were taken on the samples and values of 3 reflectance coordinates: $L^{*}$ (lightness), $a^{*}$ (redness), and $b^{*}$ (yellowness) [14] were determined. The average values of 6 consecutive measurements were calculated separately.

\subsection{Anti-Inflammatory Activity}

2.4.1. Preparation of Samples. Samples of RG, CG150, CG350, and CG750, $20 \mathrm{~g}$ each, were soaked in $100 \mathrm{~mL}$ of distilled water for $30 \mathrm{~min}$, stirring with a glass rod, decocted for $30 \mathrm{~min}$ before filtration. The first portion of water extract was collected. The residue material then underwent the second and third extractions with boiling water, each for 30 minutes, and the second and third portions of the extract were collected. The three portions were combined and concentrated through rotary evaporation at $45^{\circ} \mathrm{C}$. Finally, 
the extract was concentrated to $20 \mathrm{ml}$. The sample extract with a concentration of $1 \mathrm{~g} / \mathrm{ml}$ was prepared.

2.4.2. RAW264.7 Cells Culture. The RAW264.7 cells were purchased from the National Infrastructure of Cell Line Resource. The cells were cultured in Dulbecco's Modified Eagle's Medium (DMEM) medium containing 10\% fetal bovine serum, $1 \%$ penicillin and streptomycin, and grown in incubators at $37^{\circ} \mathrm{C}$ and $5 \% \mathrm{CO}_{2}$. DMEM was replaced every two days, and cells were allowed to subculture when they reached $80 \%-90 \%$ confluency.

2.4.3. RAW264.7 Cells Viability Assay. Raw 264.7 cells were treated with extract solution of different concentrations of RG, CG150, CG350, and CG750 (100, 250, 500, 750, 1000, 1500,2000 , or $2500 \mathrm{mg} / \mathrm{ml}$ ). After $24 \mathrm{~h}$ incubation, the medium was removed following incubation, and $20 \mu \mathrm{L}$ of MTT $(5 \mathrm{mg} / \mathrm{mL})$ was added into the wells and incubated for another $4 \mathrm{~h}$. Finally, $150 \mu \mathrm{L}$ of DMSO was added, and the absorbance at $490 \mathrm{~nm}$ was determined. The experiments were repeated three times independently. Cell viability $=($ experimental pore/blank pore $) \times 100 \%$.

2.4.4. NO Determination. RAW264.7 cells were seeded on 96-well plates at a density of $1 \times 10^{5}$ cells $/ \mathrm{ml}$. The cells were incubated at $37^{\circ} \mathrm{C}$ and $5 \% \mathrm{CO}_{2}$. RAW264.7 cells were treated with LPS $(1 \mu \mathrm{g} / \mathrm{mL})$, LPS + quercetin $(5 \mu \mathrm{g} / \mathrm{mL})$, LPS + RG $(100,250$, or $500 \mathrm{mg} / \mathrm{ml}), \mathrm{LPS}+\mathrm{CG} 150(100,250$, or $500 \mathrm{mg} /$ $\mathrm{ml})$, LPS + CG350 $(100,250$, or $500 \mathrm{mg} / \mathrm{ml})$, and LPS + 750 $(100,250$, or $500 \mathrm{mg} / \mathrm{ml})$. All the agents were added at the same time, and the groups were treated for $24 \mathrm{~h}$. The supernatant of cells was mixed with an equal volume of Griess reagent, and the absorbance of the mixture was measured at $540 \mathrm{~nm}$. The experiments were repeated three times independently.

\subsection{Bacteriostatic Activity}

2.5.1. E. coli Viability Assay. E. coli (ATCC 8739) was placed in a triangular flask containing $100 \mathrm{ml}$ Luria-Bertani broth medium and cultured for $20 \mathrm{~h}$ in a constant temperature rotary shaker at $37^{\circ} \mathrm{C}$. All samples were sterilized in an autoclave $\left(121^{\circ} \mathrm{C}, 15 \mathrm{~min}\right)$ before microbial testing to remove any environmental bacteria. After sterilization, cool to room temperature. $1 \mathrm{ml}$ of bacterial suspension $\left(\sim 10^{8} \mathrm{CFU} / \mathrm{ml}\right)$ was added to media containing $20 \mathrm{~g}$ sterilized samples and cultured for $20 \mathrm{~h}$ at a rate of $150 \mathrm{r} / \mathrm{min}$ at a constant temperature in a rotary shaker at $37^{\circ} \mathrm{C}$. The mixture of bacteria and samples cultured in Luria-Bertani medium was continuously diluted to $10^{8}$ times, and $100 \mu \mathrm{l}$ was taken and evenly coated on Luria-Bertani agar plate and incubated in an incubator for 20 hours. Finally, the number of colonies on the agar plate was observed.

2.5.2. Morphology Observation of E. coli. On treatment with RG, CG150, CG350, and CG750, specific morphological changes of Escherichia coli (ATCC 8739) were observed by
FESEM (JSM-7001F, Japan). E. coli was cultured in $250 \mathrm{ml}$ triangular flasks with $5 \mathrm{~g} / \mathrm{ml} \mathrm{RG}$, CG150, CG350, and CG750 for 7 and 14, respectively. At 7 and 14, respectively, $1 \mathrm{ml}$ of bacterial liquid was sucked, centrifuged, and separated ( $8000 \mathrm{rpm}, 10 \mathrm{~min})$ to obtain the bacterial bodies, washed three times with PBS, and finally fixed with $2.5 \%$ glutaraldehyde fixative for $4 \mathrm{~h}$. Then, the samples were then dehydrated by increasing ethanol concentrations $(30,50,70$, $80,90,95$, and $100 \%$ ) for 10 min each time. E. coli grown in the blank medium was employed as a control. The bacterial morphology was fixed with $2.5 \%$ gluta fixation fluid. After being dried in air at room temperature and coated by gold sputter, samples were examined with FESEM.

\subsection{Scald Healing Assay}

2.6.1. Animals. 126 SPF male Kun Ming (KM) mice weighing $20-25 \mathrm{~g}$ were purchased from Beijing Vital River Laboratory Animal Technology Co., Ltd. (License number: SCXK (Jing) 2016002, Beijing, China). The mice were raised in the animal feeding room of BUCM under specified conditions, i.e., temperature: $22 \pm 2^{\circ} \mathrm{C}$; relative humidity: $50 \pm 5 \%$; and $12 / 12 \mathrm{~h}$ light-dark cycle. All the methods and procedures of animal experiments were audited and approved by the Animal Experimental Welfare Ethics Committee of BUCM (BUCM-4-2019051002-2100).

2.6.2. Treatment and Assessment of Scald Healing. The scald model was created using the method described by Said et al. [15] with some modifications. For scald wound infliction, the animals were first anesthetized with pentobarbital sodium ( $50 \mathrm{mg} / \mathrm{kg}$, b. w.), followed by removal of hairs from the dorsal area of mice using a hair trimmer. The model was established by heating copper sheets to induce skin scald $\left(200^{\circ} \mathrm{C}, 3 \mathrm{~s}\right)$ with a wound diameter of $1.5 \mathrm{~cm}$ on the back of mice.

Preparation of ointment: RG, CG150, CG350, and CG750 were mixed with sesame oil in the ratio of $4: 6$, respectively, and RG ointment, CG150 ointment, CG350 ointment, and CG750 ointment were prepared.

A total of 126 animals were used and divided into 7 different groups (normal group, model group, RG group, CG150 group, CG350 group, CG750 group, and positive control group, $n=18$, respectively), each having 6 animals. The model group was treated with sesame oil and considered as vehicle control. The RG group was topically treated with RG ointment; the CG150 group was topically treated with CG150 ointment; the CG350 group was topically treated with CG350 ointment; and the CG750 group was topically treated with CG750 ointment. The positive control group was topically treated with Jingwanhong Scald Ointment (JSO) purchased from Tianjin Darentang Jingwanhong Pharmaceutical Co., Ltd. (batch number: Z12020440, Tianjin, China). The treatment was given two times a day for 21 days.

On 5, 10, and 15 days after injury, 6 animals in each group were anesthetized and euthanized by intraperitoneal pentobarbital sodium injection $(150 \mathrm{mg} / \mathrm{kg}$, b. w.). Then, the 
skin tissues from the wound site were excised for histological observation and immunohistochemical study. For histological and immunohistochemical analyses, tissues were fixed in $10 \%$ formalin at room temperature, and unbound fixative was removed by washing in PBS.

2.6.3. Histopathological Observation. The formalin-fixed tissue specimens were dehydrated by passing through gradient alcohol of 90\%, 95\%, and then absolute alcohol for 5, 5, and $5 \mathrm{~min}$, respectively. This was followed by removing alcohol in the xylene solution and, finally, embedded in hot paraffin to prepare blocks. Blocks of a tissue section of $5 \mu$ thickness were cut with a microtome. Hematoxylin and eosin (H\&E) staining was used to show the morphology of skin tissue. Slice images were captured and digitized by a microscope (Nikon Eclipse Ti-SR, Nikon, Japan).

2.6.4. Immunohistochemical Analysis. On 5, 10, and 15 days after injury, the expression of IL- $1 \beta$ and TGF was detected by immunohistochemistry in wound tissue sections. Immunohistochemical reactions were performed and incubated overnight at $4^{\circ} \mathrm{C}$. Then, they were incubated with a secondary antibody (DAKO, China) for 50 minutes. After adequate diaminobenzidine staining and hematoxylin counterstaining, the positive expression can be observed and recorded under the microscope. The integrated optical density (IOD) was quantitatively analyzed using ImagePro Plus software (Media Cybernetics, USA).

2.7. Statistical Analysis. SPSS 16.0 software was used for statistical analysis, and one-way ANOVA and Student's $t$ test were used. All data were expressed as the mean\pm standard deviation. $P<0.05$ was considered significant, and $P<0.01$ was considered extremely significant.

\section{Results}

3.1. FTIR Spectroscopy Analysis. As shown in Figure 1(A), the main phase composition of RG is gypsum. It is conclusive that the IR absorption bands of RG are located at around $1620 \mathrm{~cm}^{-1}$ and $1687 \mathrm{~cm}^{-1}$ (bending vibration $\mathrm{H}_{2} \mathrm{O}$ ), $3405 \mathrm{~cm}^{-1}$ and $3545 \mathrm{~cm}^{-1}$ (stretching vibration $\mathrm{H}_{2} \mathrm{O}$ ), $601 \mathrm{~cm}^{-1}$ and $668 \mathrm{~cm}^{-1}$ (bending vibration $\mathrm{SO}_{4}{ }^{2-}$ ), and $1115 \mathrm{~cm}^{-1}$ and $1141 \mathrm{~cm}^{-1}$ (stretching vibration $\mathrm{SO}_{4}{ }^{2-}$ ) $[1,16]$.

As revealed in Figure 1(B), compared with RG, the intensity of the IR absorption peak of CG150 for bending vibration $\left(1620 \mathrm{~cm}^{-1}, 1687 \mathrm{~cm}^{-1}\right)$ and stretching vibration $\left(3405 \mathrm{~cm}^{-1}\right.$ and $\left.3545 \mathrm{~cm}^{-1}\right)$ of $\mathrm{H}_{2} \mathrm{O}$ decreased, corresponding to bassanite [17]. For CG350 (Figure 1(C)), there was a great deal of loss in absorbance at bending vibration and stretching vibration of $\mathrm{H}_{2} \mathrm{O}$. CG350 FTIR peaks at $673 \mathrm{~cm}^{-1}$ and $1155 \mathrm{~cm}^{-1}$ were attributed to anhydrite III [7]. For CG750, as shown in Figure 1(D), any bending vibration and stretching vibration of $\mathrm{H}_{2} \mathrm{O}$ were not detected, and the IR absorption peak of CG750 was located at $594 \mathrm{~cm}^{-1}$, $613 \mathrm{~cm}^{-1}$, and $676 \mathrm{~cm}^{-1}$, demonstrating that the main phase of CG750 was anhydrite II [7].

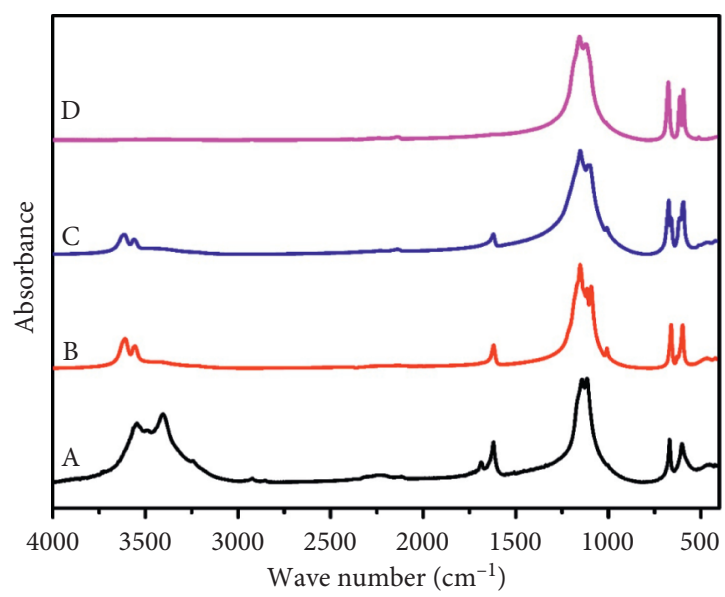

FIgURE 1: The infrared spectrum of RG (a), CG150 (b), CG350 234 (c), and CG750 (d).

3.2. XRD Spectroscopy Analysis. XRD was employed to analyze the phase composition changes of samples. XRD data were further processed by Jade 9 software for phase analysis. In Figure 2, the diffraction pattern of RG is consistent with the PDF file no.04-008-9805 (gypsum), showing that the main crystal structure of RG is gypsum; three prominent diffraction peaks correspond to (020), (040), and (041) crystal faces of the standard peak. The diffraction pattern of CG150 is consistent with the PDF file no. 97038-0286 (bassanite), and four weak peaks correspond to (200), (020), (220), and (204) crystal faces, indicating that the main crystal structure of CG150 is bassanite. CG350 pattern matches the PDF file no. 04-011-1764 (anhydrite III); four weak peaks correspond to (110), (310), (400), and (112) crystal faces, illustrating that the main crystal structure of CG350 is anhydrite III. The diffraction pattern of CG750 is in keeping with the PDF file no. 04-008-2486 (anhydrite II); four weak peaks corresponding to (020), (210), (202), (220), and (212) crystal faces, illustrating that the main crystal structure of CG750 is anhydrite II. The results are in good agreement with those of FTIR.

Integrating FTIR and XRD detection results, we confirmed that the phase structures of RG, CG150, CG350, and CG750 are gypsum, bassanite, anhydrite III, and anhydrite II in order. In the next study, we will explore these four different phase structures' mineralogical properties, their antibacterial and anti-inflammatory effects, and their healing effects on scald injuries.

3.3. SEM Observation. SEM images clearly showed differences in texture among RG, CG150, CG350, and CG750 (Figure 3). As shown in Figure 3(a), no defects were observed on RG particles' surface, and the surface is plate-like and overlapped. While, small cracks appeared on the outside of CG150, as shown in Figure 3(b). For CG350, there are many pore structures with faults, and the marks are arranged longitudinally parallel. However, interestingly, the surface of CG750 began to appear as small and dense cracks instead of becoming looser. 


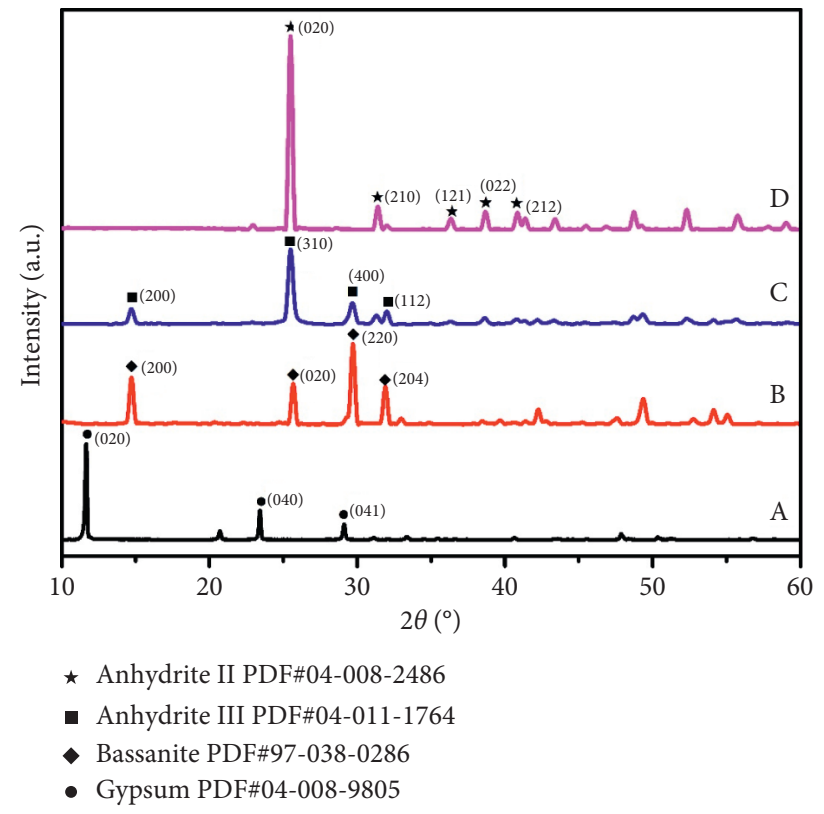

Figure 2: The XRD patterns of RG (A), CG150 (B), CG350 (C), and CG750 (D).
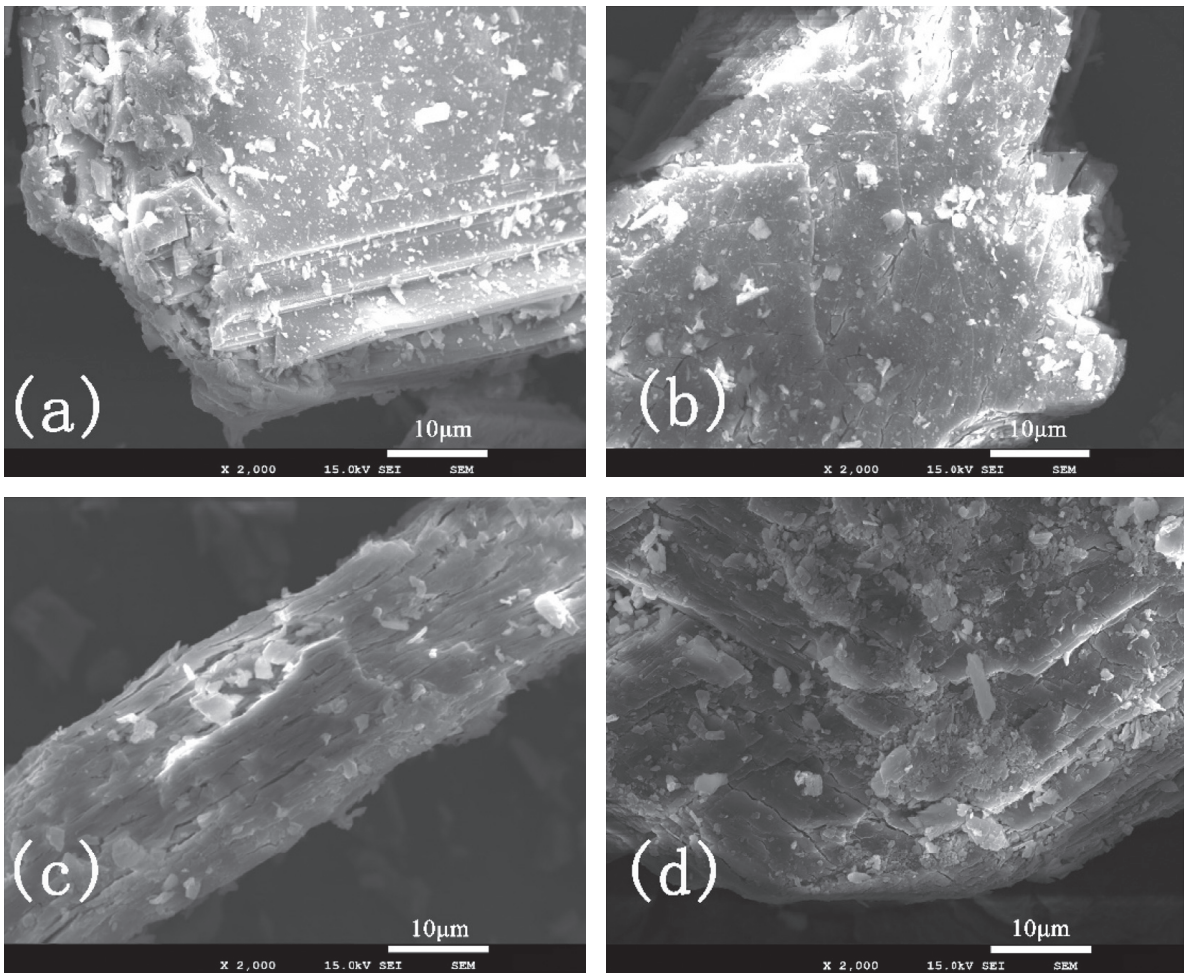

Figure 3: The SEM images of (a) RG, (b) CG150, (c) CG350, and (d) CG750.

According to the description of CG [2], loose and fragile means better quality. From our results, we can see that the order of the cracks on CGs from large to small is CG350, CG150, CG750, and RG; the corresponding phase structures are anhydrite III, bassanite, anhydrite II, and gypsum.
3.4. SAPA Measurement. The $\mathrm{N}_{2}$ adsorption-desorption isotherms of RG, CG150, CG350, and CG750 powders are shown in Figure 4. The $\mathrm{N}_{2}$ adsorption-desorption isotherms of RG and CG750 followed type III with an H1 hysteresis loop [18] in the relative pressure range of $0.8-1.0$, which 


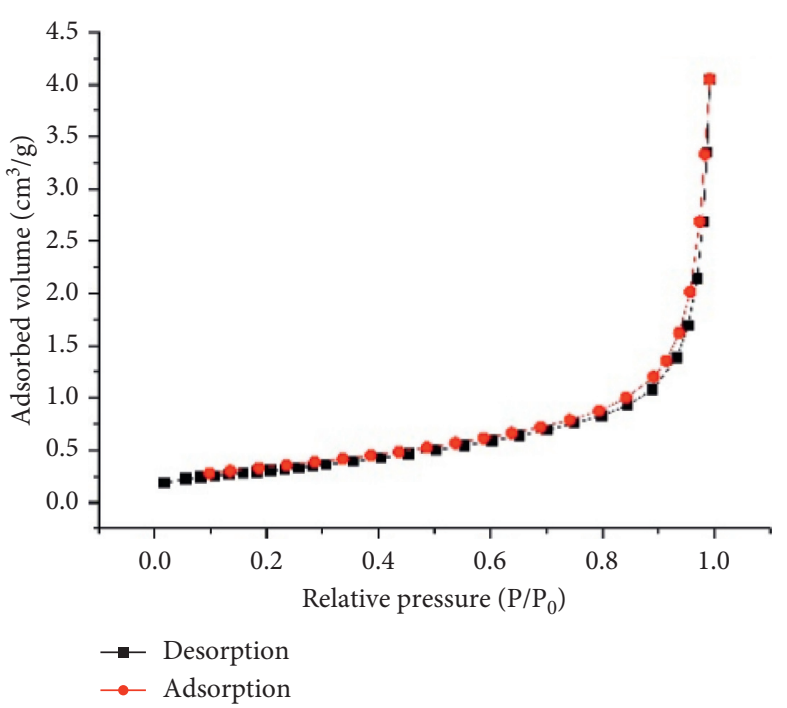

(a)

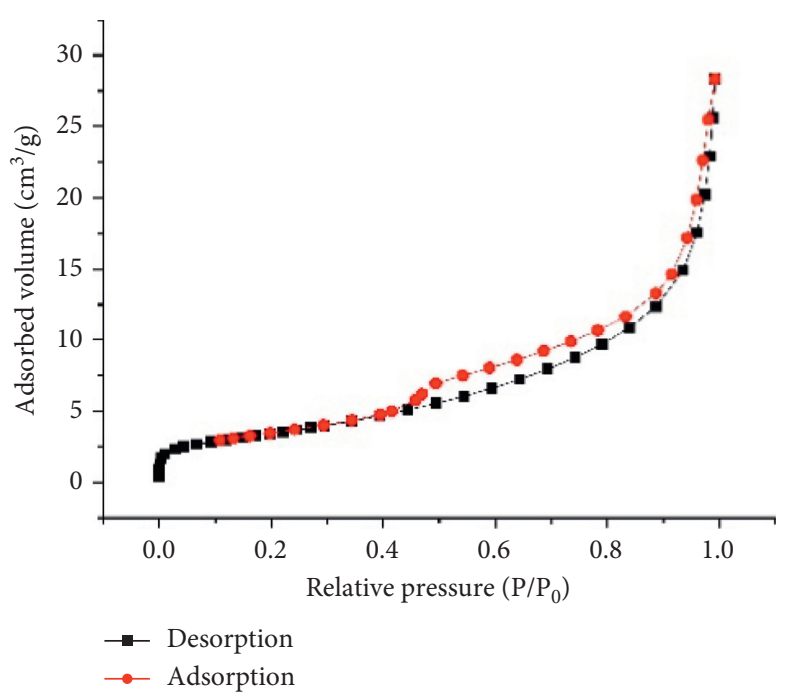

(c)

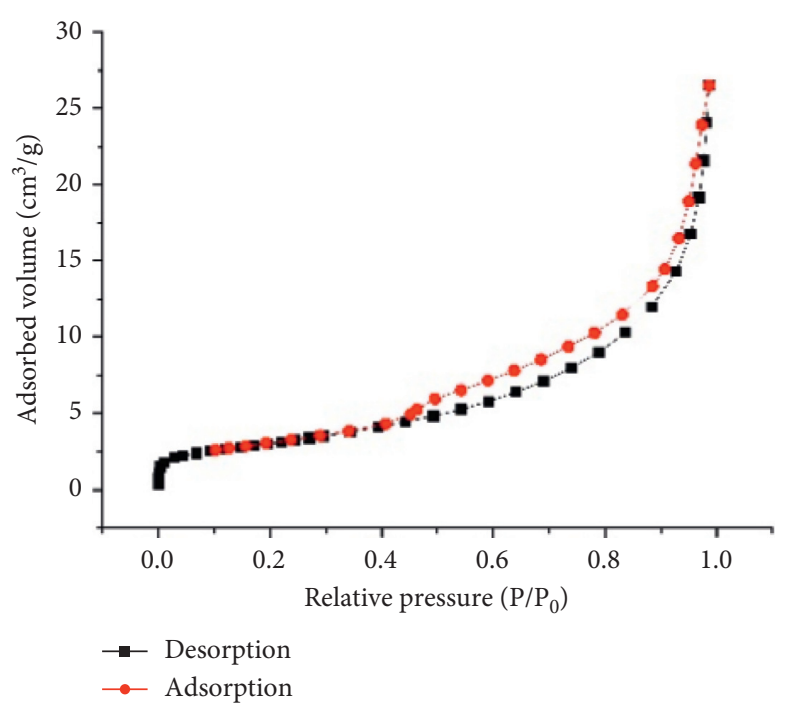

(b)

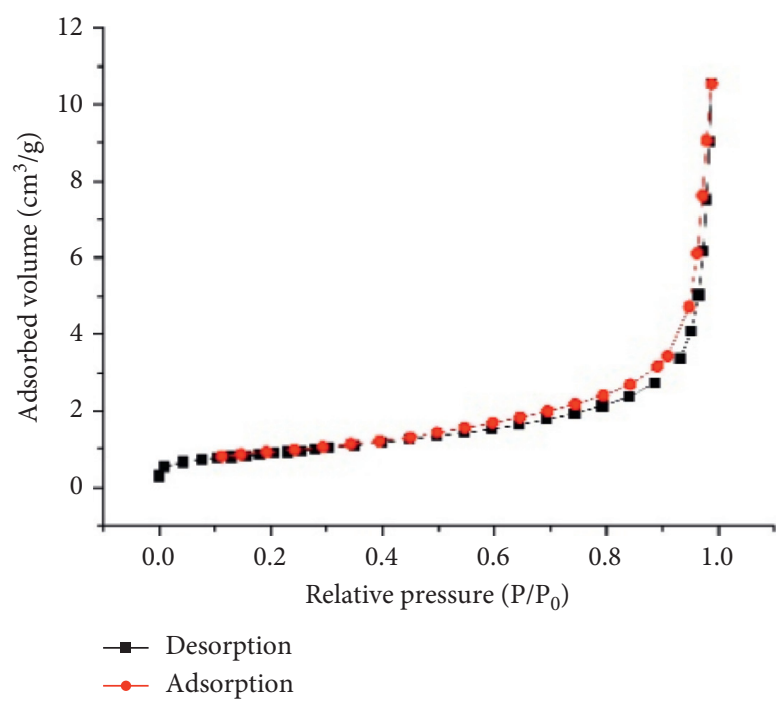

(d)

FIGURE 4: Nitrogen adsorption-desorption isotherms of (a) RG, (b) CG150, (c) CG350, and (d) CG750 powder.

means that the powder has macroporous characteristics. The $\mathrm{N}_{2}$ adsorption-desorption isotherms of CG150 and CG350 were consistent with type IV with an H3 hysteresis loop [18] in the relative pressure range of $0.4-1.0$, which means that the characteristics of the materials are mesoporous [19].

It can be seen from Table 1, as the calcination temperature of $R G$ rises from $150^{\circ} \mathrm{C}$ to $750^{\circ} \mathrm{C}$, the specific surface area and pore volume of the calcined products first increase and then decrease. Among RG, CG150, CG350, and CG750, CG150 and CG350 had the larger specific surface area and pore volume. The increase of the specific surface area and pore volume of CG150 and CG350 may be due to dehydration and dehydroxylation reactions in gypsum with the increase of calcination temperature [20]. When the calcination temperature is set at $750^{\circ} \mathrm{C}$, due to the influence of high temperature, the internal chemical bonds of CG750 are broken, and the molecular structure is rearranged, resulting in smaller pore volume and specific surface area [21]. The relatively large surface area and pore volume mean more space to absorb exudate and keep the wound surface dry for external use. The experimental results are consistent with those of SEM observation.

3.5. Colour Measurement. The colorimetric characteristics, lightness $\left(\mathrm{L}^{*}\right)$, redness $\left(\mathrm{a}^{*}\right)$, and yellowness $\left(\mathrm{b}^{*}\right)$ values are presented in Figure 5(b). The $L^{*}$ value results showed that the colour of all the calcined samples is lighter than the gypsum. From the detected $a^{*}$ value results, it can be found that the colour of gypsum gradually turns to red after calcination: the colour of CG750 is redder than that of CG350 and CG150, and the colour of CG350 is redder than that of CG150. CG750, CG350, and CG150's $b^{*}$ value measured with the colorimeter was significantly higher than that of $\mathrm{RG}$, meaning that the colour of calcined samples was yellow, and the order of yellowness was CG350 > CG750 > CG150. 
TABLe 1: The textural properties of RG, CG150, CG350, and CG750 powder.

\begin{tabular}{|c|c|c|c|c|}
\hline Sample & RG & CG150 & CG350 & CG750 \\
\hline BET surface area $\left(\mathrm{m}^{2} / \mathrm{g}\right)$ & 1.1215 & 11.0159 & 12.5437 & 3.1734 \\
\hline Pore volume $(\mathrm{ml} / \mathrm{g})$ & 0.0063 & 0.0409 & 0.0438 & 0.0163 \\
\hline Average pore size $(\mathrm{nm})$ & 22.4699 & 14.8513 & 13.9672 & 20.5458 \\
\hline
\end{tabular}
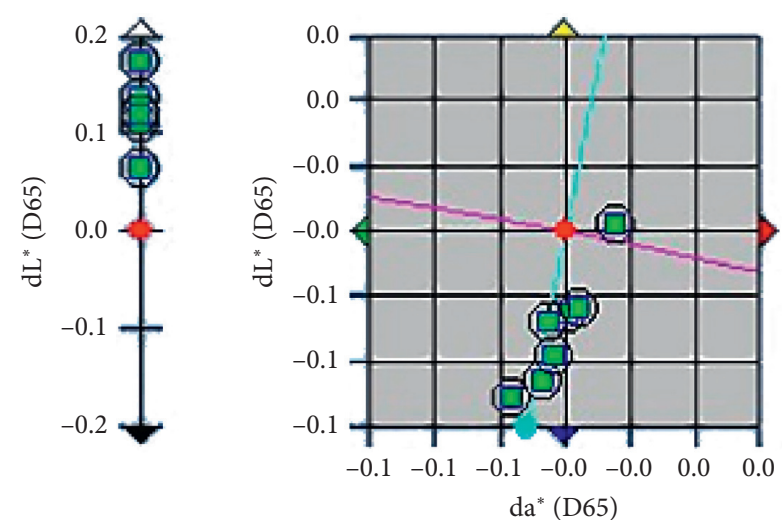

RG
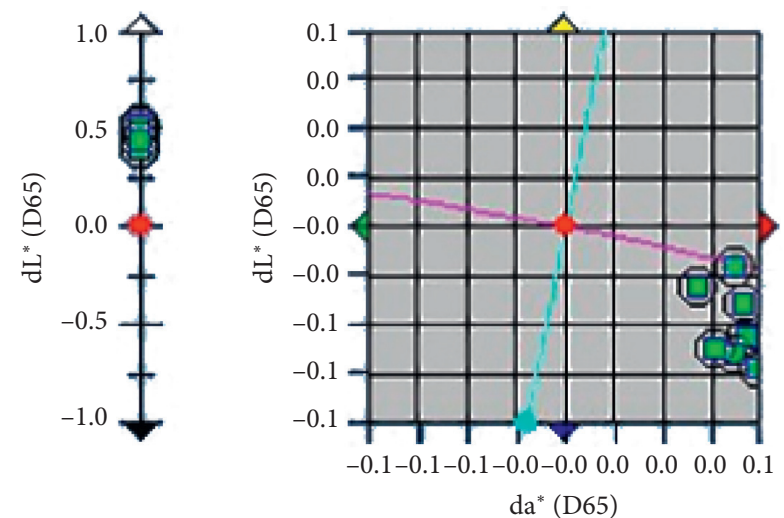

CG350

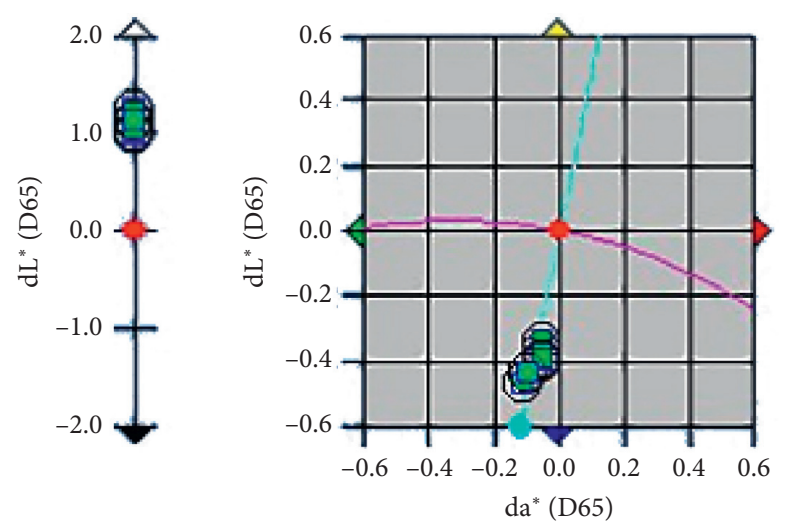

CG150
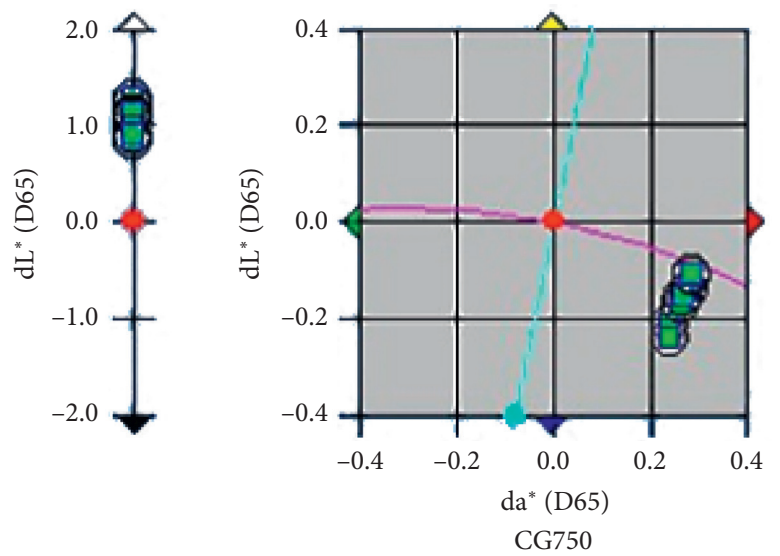

(a)
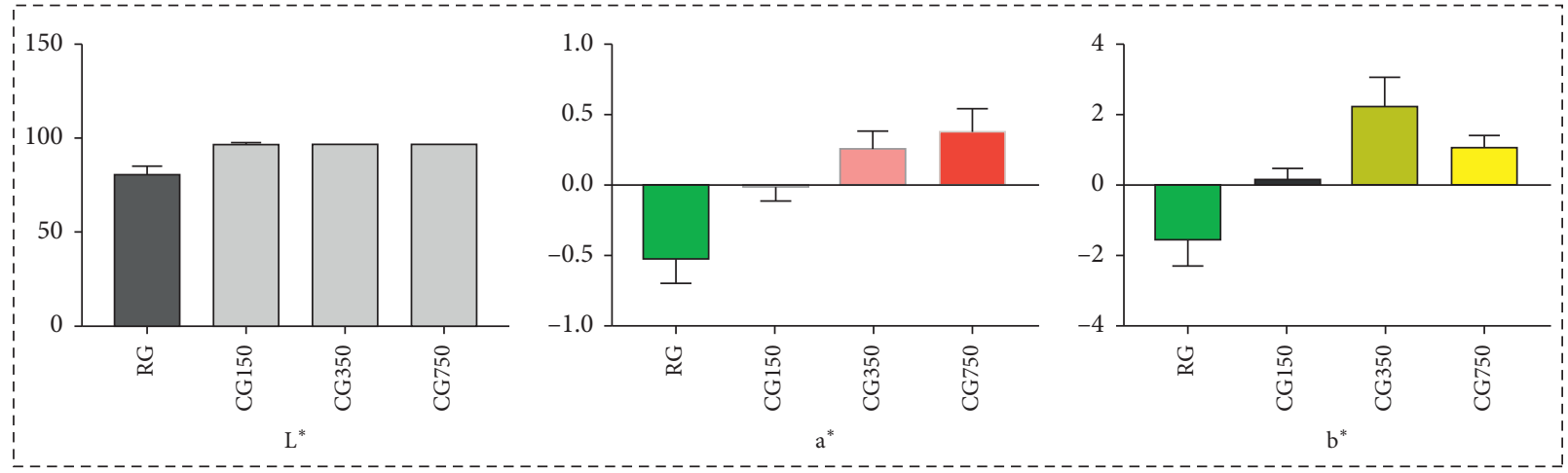

(b)

Figure 5: (a) Instrumental colour $\mathrm{dL}^{*}$ values, $\mathrm{da}^{*}$ values, and $\mathrm{db}^{*}$ values' scatter diagram of RG, CG150, CG350, and CG750. (b) Instrumental colour $L^{*}$ values, $a^{*}$ values, and $b^{*}$ values of RG, CG150, CG350, and CG750 (values within each column with different letters are significantly different $(P<0.05))$.

Shape, colour, smell, and texture are the traditional indicators commonly used to evaluate the quality of Chinese medicine. However, the application of them is limited due to the difficulty of quantification and the high dependence on experience. Many evaluation methods based on colour measurement have been developed in modern times to 
evaluate the quality of traditional Chinese medicine [22]. According to the Chinese Pharmacopoeia, CG should be white and opaque with red lustre [2]. However, it is difficult to distinguish the difference between samples with the naked eye. Colour as an appearance indicator of CG has not been determined by a quantitative method. Our colour measurement results also provide a reference for the quality control of CG.

\subsection{Cell Experiment Results}

3.6.1. Effect on the Viability of RAW 264.7 Cells. The effects of RG, CG150, CG350, and CG750 on RAW264.7 cell viability are shown in Figure 6. On treatment with 100, 250, or $500 \mathrm{mg} / \mathrm{ml}$, the cell viability was above $90 \%$, implying that RG, CG150, CG350, and CG750 did not produce harmful toxicity. The LD50 of the RG group was $2853 \mathrm{mg} / \mathrm{ml}$, that of the CG150 group was $1933 \mathrm{mg} / \mathrm{ml}$, that of the CG350 group was $1304 \mathrm{mg} / \mathrm{ml}$, and that of the CG750 group was $1685 \mathrm{mg} /$ $\mathrm{ml}$. Samples significantly decreased the cell viability at $1000 \mathrm{mg} / \mathrm{ml}$ and $2000 \mathrm{mg} / \mathrm{ml}(P<0.01)$. Therefore, concentrations of 100,250 , and $500 \mathrm{mg} / \mathrm{ml}$ of samples were selected for further investigation.

3.6.2. Effects on NO Production in LPS-Induced RAW264.7 Cells. To evaluate the effect of RG, CG150, CG350, and CG750 on inflammation, the LPS-induced inflammation model was successfully established. As shown in Figure 7, compared with the LPS model group, the NO expression level in the quercetin-positive group was significantly decreased $(P<0.01)$. All samples had inhibitory effects on NO production in LPS-induced RAW264.7 cells $(P<0.01)$. The inhibitory effects of CG150 and CG350 on the release of NO were stronger than those of RG and CG750 $(P<0.01)$, and there was no significant difference between the effects of CG150 and CG350 $(P>0.05)$.

$\mathrm{NO}$ can be stimulated by a variety of harmful stimuli, such as pathogens, damaged cells, or irritants [23]. Excessive production of $\mathrm{NO}$ can induce chronic inflammation in macrophages $[24,25]$. Our results showed that RG, CG150, CG350, and CG750 could dose-dependently inhibit the production of NO produced by LPS-stimulated cells, while CG350 and CG150 have a stronger effect. All these indicate that CG150 and CG350 will perform better in the inflammatory response induced by injuries such as burns or ulcers, compared with RG and CG750.

\subsection{Bacteriostatic Experiment Results}

3.7.1. Antibacterial Activity. In Figure 8, there was no significant difference in the number of colonies in the RG group compared with the control group, which implied that RG has no inhibitory effect on $E$. coli. It is worth noting that the inhibition rate of CG350 on E. coli was $91.26 \pm 7.33 \%$. However, CG750 exhibited lower antibacterial activity, with its inhibition rate at $35.54 \pm 0.57 \%$, and the inhibition rate of CG150 was $65.50 \pm 12.43 \%$. So, CG350 performs obvious bacteriostatic advantages on E. coli, compared to RG,
CG150, and CG750 $(P<0.05)$. The differences in the bacteriostatic effect between samples were unexpected. Our results indicated that all CG samples exhibit bacteriostatic effects after calcination, while CG samples with different phase structures showed a different antibacterial effect.

Bacterial infections are very common in burns and other traumas [26]. European Wound Management Association (2005) described that E. coli is an important organism causing wound infections [27]. Our results showed that CG350 has an excellent effect in inhibiting $E$. coli, which provides a piece of evidence for CG350 as a better phase structure for external use. However, the antibacterial effects of CG with different phase structures on other bacteria still need to be further studied to support this conclusion.

3.7.2. Bacterial Morphological Changes. The morphology of E. coli after being cultured with RG, CG150, CG350, and CG750 for $7 \mathrm{~h}$ and $14 \mathrm{~h}$ is shown in Figure 9. Under normal conditions, E. coli is short rod-shaped and have a smooth surface; their diameter is about $800 \mathrm{n}$. Compared with the control group, RG showed no effect on the cell membrane of E. coli at both $7 \mathrm{~h}$ and $14 \mathrm{~h}$, while CG150, CG350, and CG750 excreted different degrees of damage to the cell membrane. Compared with normal E. coli, the shape of $E$. coli that interacted with CG150 and CG350 became irregular. The cell membrane was damaged and could not be kept intact. The membrane and structure of E. coli interacted with CG350 were more seriously damaged and broken compared with CG150 and CG750. The results of the influence on the morphology of E. coli are consistent with those of the antibacterial effect on E. coli.

Infection is one of the severe complications of trauma [28]. Over the past decades, many studies have confirmed this view that microorganisms are critical causes of delayed healing and infection of acute or chronic burn wounds $[29,30]$. E. coli is the most common pathogen causing wound infection [31]. However, most pathogenic bacteria's resistance increases year by year with the widespread use of antibiotics [32]. It is urgent to find nontoxic materials to resist bacterial infection. CG is a widely used external medicine for wound healing in Chinese medicine. Pathogenic bacteria easily infect wounds after formation, so inhibiting the growth of bacteria is an important indicator to evaluate the efficacy of CG. In this experiment, CG showed a strong antimicrobial effect.

\subsection{Results of Histopathological Analysis}

3.8.1. Histopathological Examinations. As shown in Figure 10, histological observations of wounds in different groups are presented. The normal anatomy of skin tissues stained with H\&E showed healthy granulation, hair follicles, epithelial cells, fibroblast cells, blood vessels, epithelial, epidermal, and dermal layers (Figure 10).

On the 5th day, in the RG group and CG150 group, skins had more severe damage to the epidermal tissue, a large number of necrotic tissue debris, pus cells, adipocyte cavities, and exudates formed by the crust structure covering, 


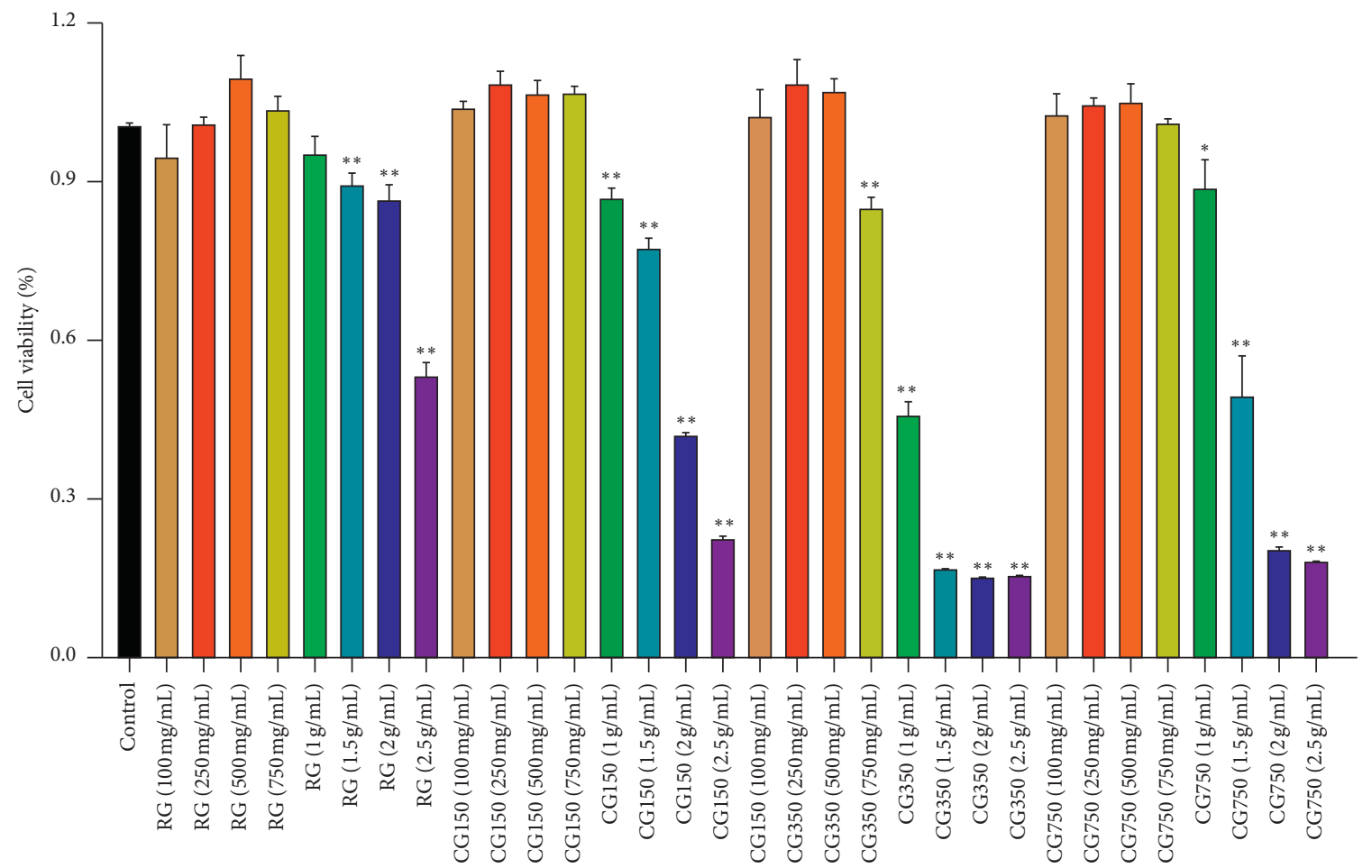

Figure 6: RAW264.7 cell viability. Cells were treated with different concentrations of RG, CG150, CG350, and CG750 for 24 h, and cell viability was measured using an MTT assay $\left({ }^{* *} \mathrm{P}<0.01\right.$ and ${ }^{*} \mathrm{P}<0.05$ vs. control).

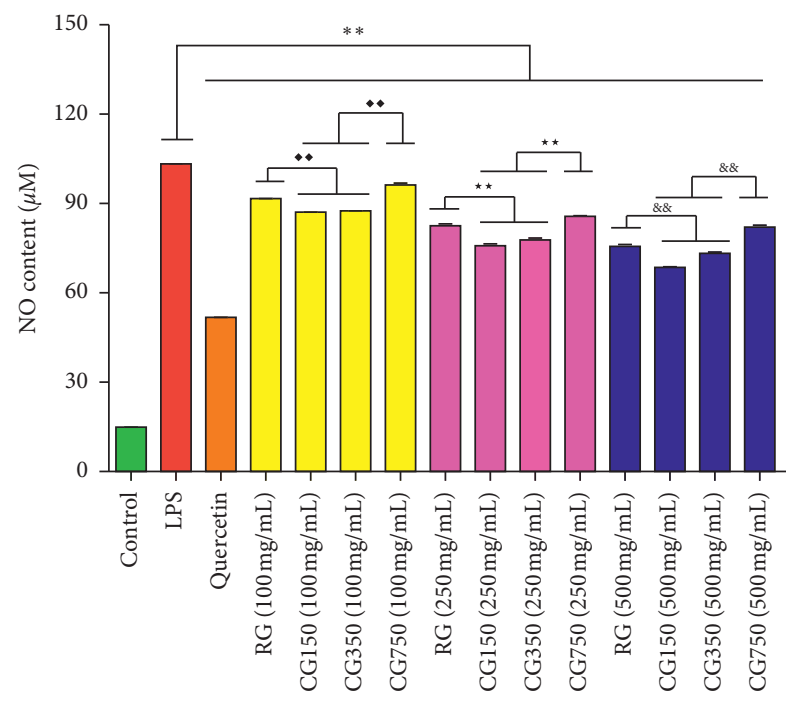

Figure 7: NO content of RG, CG150, CG350, and CG750. NO assay using the cells treated with LPS $(1 \mu \mathrm{g} / \mathrm{ml})$ in the absence or presence of RG, CG150, CG350, and CG750 at different concentrations $(100,250$, and $500 \mathrm{mg} / \mathrm{ml}$, respectively) for $24 \mathrm{~h}$ $\left({ }^{*} P<0.01\right.$ vs. LPS; $\bullet P<0.01$ vs. CG150 $(100 \mathrm{mg} / \mathrm{mL})$ and CG350 $\quad(100 \mathrm{mg} / \mathrm{mL}) ; \quad{ }^{\star \star} P<0.01 \quad$ vs. CG150 $\quad(250 \mathrm{mg} / \mathrm{mL})$ and CG350 $(250 \mathrm{mg} / \mathrm{mL}) ;{ }^{\& \&} P<0.01$ vs. CG150 $(500 \mathrm{mg} / \mathrm{mL})$ and CG350 (500 mg/mL)).

with a large number of inflammatory cell infiltration and more bleeding phenomenon. The damaged skin of the CG150 group had signs of exfoliation. In the CG350, CG750, and positive drug groups, the necrotic epidermal tissues began to recover, with tiny scabs, a small number of inflammatory cells scattered around, a small number of fibroblasts and new capillaries visible, as well as mature granulation tissue proliferation and repair, and more fibroblasts and collagen fibres visible.

On day 10, the skin of CG350, CG750, and positive drug groups recovered well and generated a large amount of mature hair follicle tissue, fat vacuoles, and arranged complete muscle tissue. The model group, RG group, and CG150 group had worse skin recovery. The model group and RG group had early hair follicle tissue generation, while the CG150 group had no hair follicle tissue generation and muscular tissue of which was also irregularly arranged.

On day 15, the skin in other groups except the CG150 group grew more mature granulation tissue, fibroblasts, collagen fibres, and many mature hair follicle tissues. Compared with other groups, the CG350 and positive drug groups had more new well-arranged hair follicle tissues and well-recovered skin blood vessels.

It is surprising in the experimental results that the effect of CG150 on wound healing is worse than that of the model group. The reason for this result may be that CG150, whose main phase structure is bassanite with strong water absorption [33], leads to excessive dryness of the wound, resulting in a secondary pus discharge from the wound [34].

3.8.2. Immunohistochemical Analysis. The expression of IL$1 \beta$ and TGF in the wound site was detected by immunohistochemistry. Immunohistochemical examination of the vital wound is summarized in Figures 11 and 12. On the $5^{\text {th }}$, 


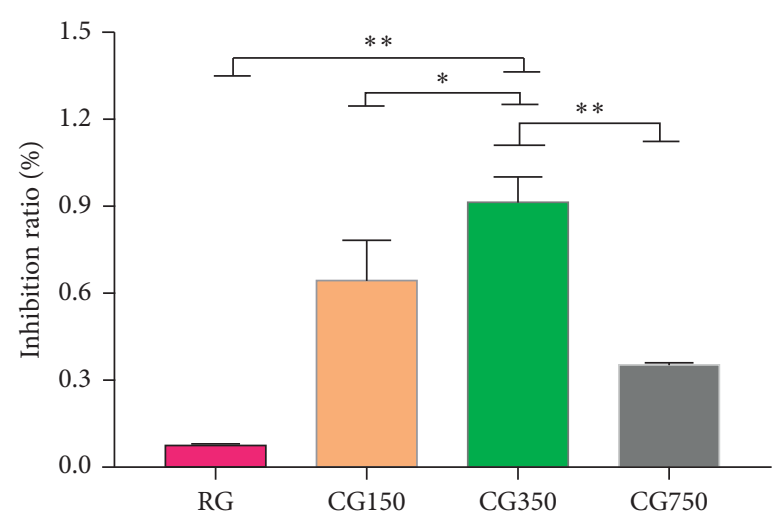

(a)

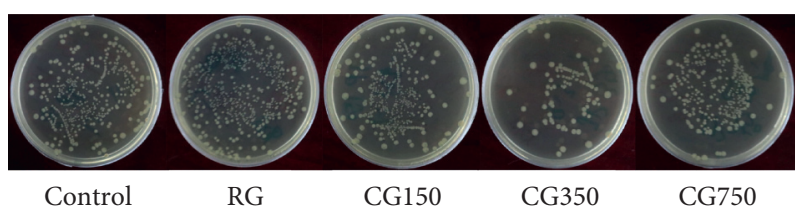

(b)

FIGURE 8: (a) Inhibition ratio of RG, CG150, CG350, and CG750 measured by a plate counting method. (b) Number of live bacteria of E. coli treated with culture medium, with $5 \mathrm{~g} / \mathrm{mL}$ of RG, CG150, CG350, and CG750 ${ }^{* *} P<0.01$ and ${ }^{*} P<0.05$ vs. CG350).
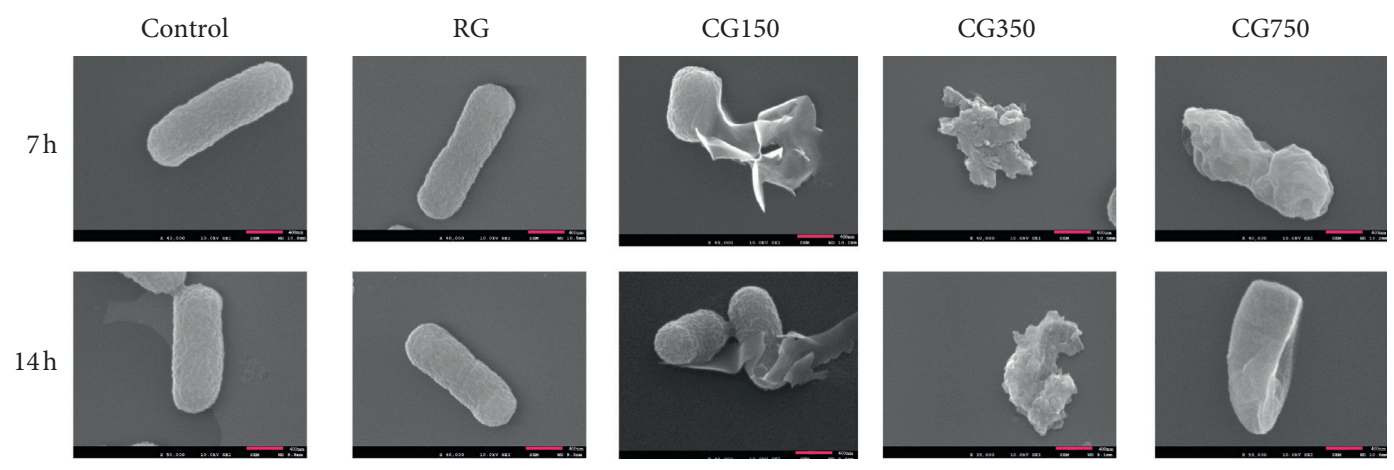

FIGURE 9: FESEM images of bacterial morphology. (a) The bacteria morphology at $7 \mathrm{~h}$. (b) The bacteria morphology at $14 \mathrm{~h}$.
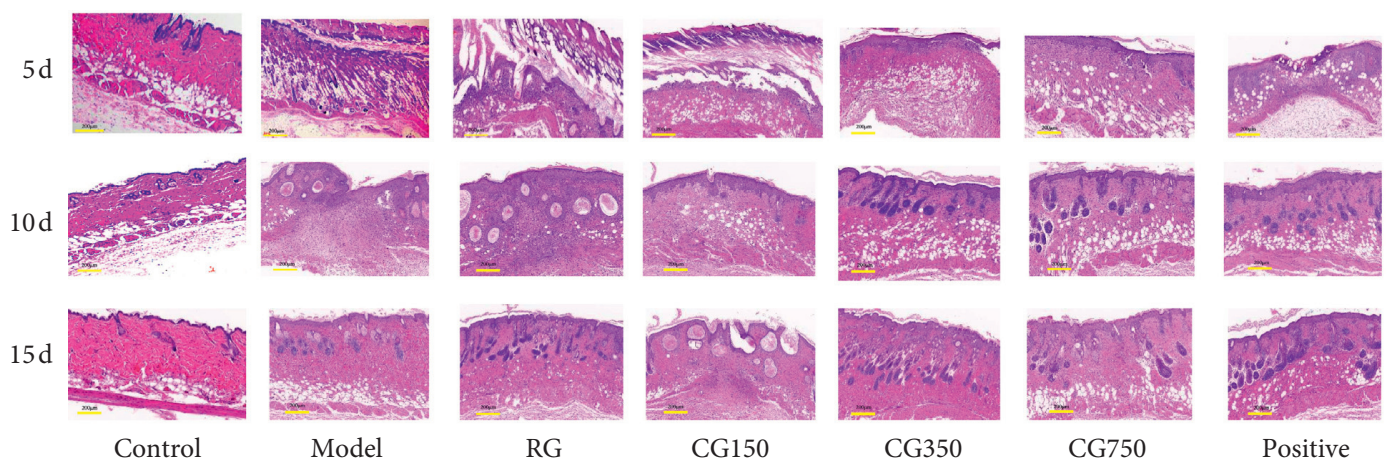

RG

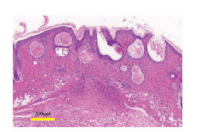

CG150

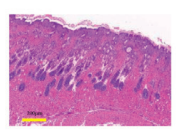

CG350

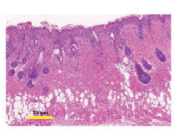

CG750

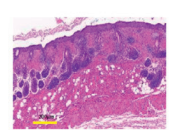

Positive

FIGURE 10: Histological appearance of scald wounds stained with hematoxylin and eosin (20x magnification, the scale is marked in the lower left corner).

$10^{\text {th }}$, and $15^{\text {th }}$ day, compared with the control group, the content of IL- $1 \beta$ in the model group was high $(P<0.01)$. On the $10^{\text {th }}$ day, compared with the model group, the IL- $1 \beta$ expression levels of CG350, CG750, and the positive groups decreased significantly $(P<0.01)$. Compared with the CG350 group, the IL- $1 \beta$ expression levels of the model, RG, CG150, and CG750 groups increased significantly $(P<0.05)$. On the $15^{\text {th }}$ day, compared with the model group, the IL- $1 \beta$ expression levels of CG350 and the positive group decreased significantly $(P<0.01)$. There was no significant difference between CG350 and the positive group $(P>0.05)$. Compared with the CG350 group, the IL- $1 \beta$ expression levels of the model, CG150, RG, and CG750 groups increased significantly $(P<0.05)$.

In terms of TGF expression, on the $5^{\text {th }}, 10^{\text {th }}$ and $15^{\text {th }}$ day, compared with the control group, the content of TGF in the model group was high $(P<0.01)$. On the $5^{\text {th }}$ day, compared with the model group, the expression of TGF in the CG350 


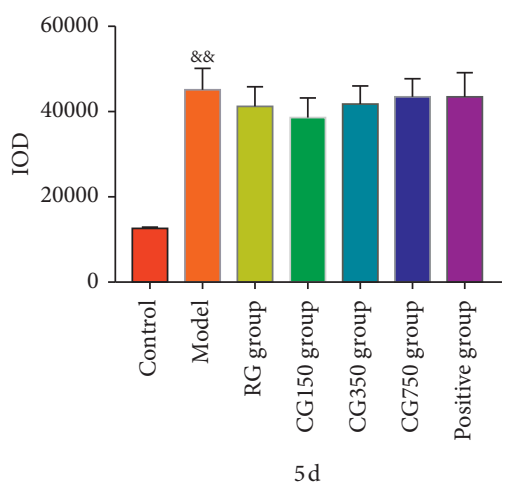

(a)

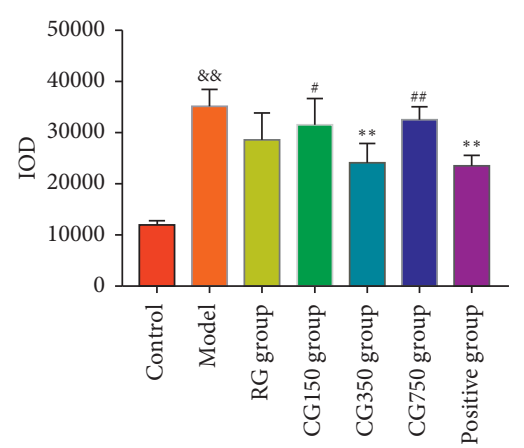

$10 \mathrm{~d}$

(b)

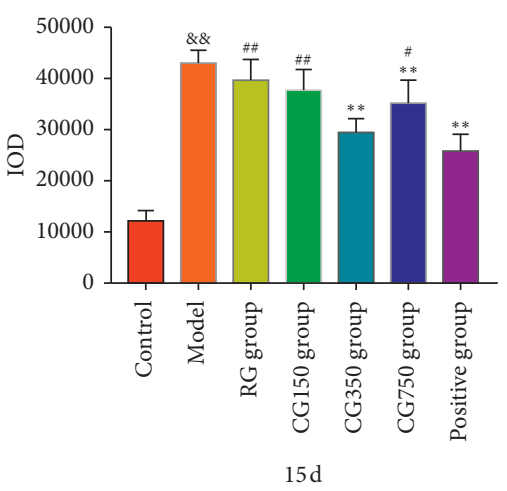

(c)

Figure 11: IL-1 $\beta$ expression levels in RG, CG150, CG350, and CG750 groups $\left({ }^{\& \&} P<0.01\right.$ vs. the control group. ${ }^{* *} P<0.01$ vs. the model group. ${ }^{\# \#} P<0.01$ and ${ }^{\#} P<0.05$ vs. the CG350 group).

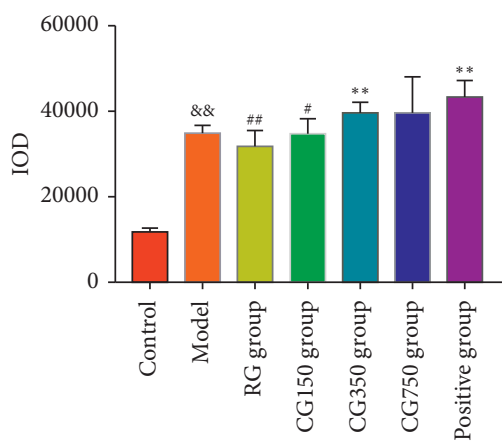

$5 \mathrm{~d}$

(a)

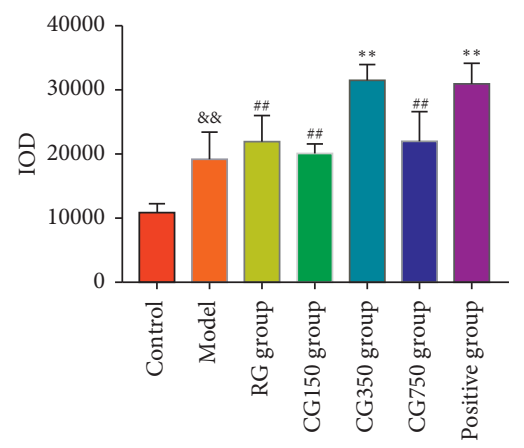

$10 \mathrm{~d}$

(b)

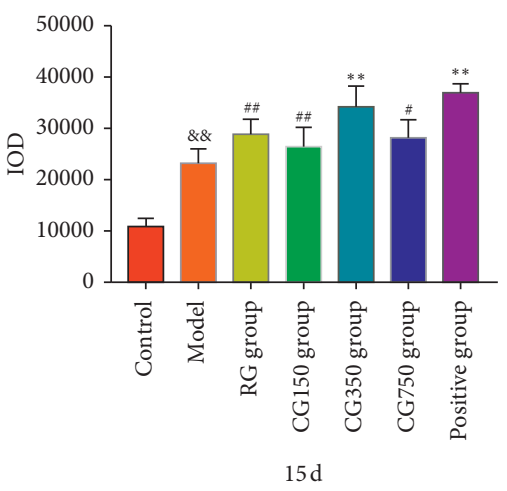

(c)

Figure 12: TGF expression levels in RG, CG150, CG350, and CG750 groups ( ${ }^{\& \&} P<0.01$ vs. the control group. ${ }^{* *} P<0.01$ and ${ }^{*} P<0.05$ vs. the model group. ${ }^{\#} P<0.01$ and ${ }^{\#} P<0.05$ vs. the CG350 group).

group and positive group was significantly higher $(P<0.01)$. Compared with the CG350 group, the TGF content of RG, CG150, and model groups was decreased $(P<0.05)$. On the $10^{\text {th }}$ day, compared with the model group, the TGF content of CG350 and positive groups was increased $(P<0.05)$. Compared with the CG350 group, the TGF content of RG, CG150, CG750, and model groups was decreased $(P<0.01)$. On the $15^{\text {th }}$ day, compared with the model group, the TGF expression of the CG350 group and positive group increased significantly $(P<0.01)$. Compared with the CG350 group, the TGF content of RG, CG150, CG750, and model groups was decreased $(P<0.05)$.

After scald injuries, a natural repair process is initiated, consisting of hemostasis, inflammation, proliferation, and remodelling [35]. High levels of proinflammatory cytokines and mediators, such as IL- $1 \beta$, delayed wound healing [36]. TGF is the primary growth factor responsible for epithelialmesenchymal transitions and has a generous contribution to skin fibrosis [37].

Our study results corroborated that CG350 had a repair effect on scalded skin. More notably, CG350 significantly downregulated the expression of IL- $1 \beta$ and upregulated the expression of TGF to improve scald wound healing.

\section{Discussion}

CG is commonly used to treat scalds and has the effects of secretion absorption, wound healing, and muscle regeneration [38]. According to traditional trait requirements, CG needs to be calcined to be opaque, brittle, and reddish [39]. During calcination, colour and texture are essential appearance indicators to control product quality. Microstructure and pore size are generally considered to be mineralogical properties related to the exudate absorbing capacity of CG. When scalds occur, wounds tend to become infected with microorganisms without treatment [40]. Following wound infection, toxic molecules and metabolites produced by persistent inflammation, bacteria, and immune responses adversely affect wound repair [41]. So far, it is still unclear how the material phase structure of CG impacts the treatment of scald wounds.

In this study, three kinds of phase structures are produced after gypsum calcination: CG150, CG350, and CG750 correspond to bassanite, anhydrite III, and anhydrite II, respectively. CG350 was the most brittle with the largest specific surface area and pore volume, followed by CG150 and CG750. RG's main component is $\mathrm{CaSO}_{4} \bullet 2 \mathrm{H}_{2} \mathrm{O}$; 
when the calcination temperature rises to $150^{\circ} \mathrm{C}$, the internal water molecules spill from the structure, the molecular structure stabilized by RG is destroyed, the spatial structure is unstable, the internal pores increase, and bassanite is generated. A larger crack appeared on the surface of CG150, and the specific surface area and pore volume increased correspondingly. When the calcination temperature was $350^{\circ} \mathrm{C}$, anhydrite III without crystallographic water was formed. CG350 showed a larger surface crack, larger specific surface area, and pore volume. Nevertheless, when the temperature increased to $750^{\circ} \mathrm{C}$, anhydrite II was formed, the structure was compact, and the specific surface area and pore volume became small. The reason is that high temperature makes CG350 internal sintering, and stable state molecules (or atoms) attract each other [42], thus forming particle binding and powder strength. In turn, the crack, specific surface area, and pore volume of CG750 are smaller than CG350. After scalding, abscesses are easily formed on the skin surface, CG350 has a large pore structure, and its phase structure is anhydrite III, which has a strong water absorption capacity [43]. Thus, CG350 can better absorb exudation in wound abscess, promoting the disappearance of the abscess, which is conducive to scald healing.

Our research group found that the calcium dissolution of RG, CG150, CG350, and CG750 was 3.17\%, 3.25\%, 4.76\%, and $3.19 \%$, respectively. The dissolution of calcium ions in samples is closely related to the pore structure. When CG150, CG350, and CG750 were in contact with water, the water molecules then moved along the channel towards the crystal's interior and interacted with the surrounding ions. After interacting with the surrounding ions, the crystal structure is destroyed, further expanding the contact surface between the crystal and water molecules, accelerating the crystal breaking and forcing $\mathrm{Ca}^{2+}$ and $\mathrm{SO}_{4}{ }^{2-}$ to move to water [44]. CG350 has the most extensive porosity, specific surface area, and pore volume, so calcium ion dissolution is the highest. Studies have shown that calcium ion plays a vital role in scald healing [45] and the anti-inflammatory effect [46]. Cadherin is a kind of cell adhesion glycoprotein with the characteristics of convergence and calcium dependence. It plays an essential role in cell recognition, migration, tissue differentiation, and adult tissue and organ composition [47]. Therefore, it is speculated that the different degrees of dissolution of calcium ions caused by the phase structure may be an important factor causing the difference in biological activity.

Based on the above analysis, the biological activity exerted by CG is closely related to the phase structure, which affects the mineralogical properties and the dissolution of calcium ions. The experimental results showed that CG350, the main phase structure of anhydrite III, exhibited more advantages in texture, pore size, specific surface area, antibacterial, anti-inflammatory, and scald repairing. FTIR and $\mathrm{XRD}$ are the most common and reliable methods to determine the phase structure $[48,49]$. In the process of calcining gypsum, FTIR and XRD are suggested to identify the phase structure of CG, which is of great significance for the quality control of CG.

\section{Conclusions}

In summary, RG, CG150, CG350, and CG750 are different in mineral properties and biological activities. RG has a dense structure, small pore size, a weak anti-inflammatory effect, but no antibacterial effect, and has almost no effect on the repair of scalds. CG150 has a loose texture, large pore size, and specific surface area and has a unique antibacterial and anti-inflammatory effect, but it has a low repair effect on scalds. CG750 has a compact structure, small pore size and specific surface area, and low antibacterial and anti-inflammatory effects, but it has a specific repair effect on scalds. Only CG350 has good properties in texture, pore size, specific surface area, antibacterial, anti-inflammatory, and scald repair. Our research has proved that, on the one hand, it is reasonable to not use RG for external use to treat trauma. On the other hand, the mineral properties and biological activities of CG are different due to different phase structures; an appropriate temperature should be selected in order to prepare CG with a better curative effect. CG350, namely, anhydrite III, is considered by our research to be the optimal phase structure for CG. Our research provides a reference for determining the best temperature for preparing CG and evaluating CG quality.

\section{Data Availability}

The data used to support the findings of this study are available from the corresponding author upon request.

\section{Ethical Approval}

Experiments were approved by the Experimental Animal Ethics Committee of Beijing University of Chinese Medicine, Beijing.

\section{Conflicts of Interest}

The authors declare that they have no conflicts of interest.

\section{Authors' Contributions}

Kaiyang Liu performed the experiments, data processing, and manuscript writing. Shu Han performed the experiments and data analysis. Wei Gao carried out experimental design and performed the experiments. Ya'nan Tang, Xitao Han, and Ziqin Liu participated in the collection and processing of tissue samples. Liyuan Bao, Meiru Zhi, and Hongyue Wang participated in mineralogical analysis. Yingli Wang carried out mineralogical experiment. Hong Du designed the study and wrote the manuscript.

\section{Acknowledgments}

This work was supported by grants from the Beijing $\mathrm{Mu}-$ nicipal Natural Science Foundation (BJNSF, 7182093), the National Natural Science Foundation of China (NSFC, 81774004), and the National Key Research and Development Plan (2018YFC1706303). 


\section{References}

[1] P. K. Mandal and T. K. Mandal, "Anion water in gypsum (CaSO4.2H2O) and hemihydrate (CaSO4.1/2H2O)," Cement and Concrete Research, vol. 32, no. 2, pp. 313-316, 2002.

[2] National Pharmacopoeia Committee, Pharmacopoeia of People's Republic of China, China Medical Science and Technology Press, vol. 2, p. 98, Beijing, China, 2020.

[3] C. Song, Z. J. Zhang, and B. L. Bian, "The hypothesis of medicinal gypsum cooling material," Spectroscopy and Spectral Analysis, vol. 40, no. 6, pp. 1716-1721, 2020.

[4] J. Zhang, M. Zhu, H. X. Xue et al., "Effect of ginseng and gypsum decoction combined with lomefloxacin hydrochloride on patients with liver-yang-hyperactivity migraine," China Journal of Pharmaceutical Economics, vol. 12, no. 11, pp. 109-111, 2017.

[5] S. Seufert, C. Hesse, F. Goetz-Neunhoeffer, and J. Neubauer, "Quantitative determination of anhydrite III from dehydrated gypsum by XRD," Cement and Concrete Research, vol. 39, no. 10, pp. 936-941, 2009.

[6] D. Gazdič, I. Hájková, and R. Magrla, "Monitoring of calcium sulphate phase transformations using high-temperature X-ray diffraction," Advanced Materials Research, vol. 864-867, pp. 621-624, 2014.

[7] N. Prieto-Taboada, O. Gómez-Laserna, I. Martínez-Arkarazo, M. Á. Olazabal, and J. M. Madariaga, "Raman spectra of the different phases in the CaSO4-H2O system," Analytical Chemistry, vol. 86, no. 20, pp. 10131-10137, 2014.

[8] Y. Li, Y. L. Wang, S. Liu et al., "The effect of temperature and time factors on the quality of calcined gypsum," Beijing Journal of Traditional Chinese Medicine, vol. 36, no. 4, pp. 368-370+372, 2017.

[9] J. M. Duke, S. M. Randall, J. H. Boyd et al., "A retrospective cohort study to compare post-injury admissions for infectious diseases in burn patients, non-burn trauma patients and uninjured people," Burns \& Trauma, vol. 6, no. 2, pp. 129-139, 2018.

[10] G. L. Rodgers, J. Mortensen, M. C. Fisher, A. Lo, A. Cresswell, and S. S. Long, "Predictors of infectious complications after burn injuries in children," The Pediatric Infectious Disease Journal, vol. 19, no. 10, pp. 990-995, 2000.

[11] D.-m. Liu, B.-w. Sun, Z.-w. Sun, Q. Jin, Y. Sun, and X. Chen, "Suppression of inflammatory cytokine production and oxidative stress by CO-releasing molecules liberated $\mathrm{CO}$ in the small intestine of thermally-injured micel," Acta Pharmacologica Sinica, vol. 29, no. 7, pp. 838-846, 2008.

[12] S. Brunauer, P. H. Emmett, E. Teller et al., "Adsorption of gases in multimolecular layers," Journal of the American Chemical Society, vol. 60, no. 2, pp. 309-319, 1938.

[13] E. P. Barrett, L. G. Joyner, and P. P. Halenda, "The determination of pore volume and area distributions in porous substances. I. Computations from nitrogen isotherms," Journal of the American Chemical Society, vol. 73, no. 1, pp. 373-380, 1951.

[14] K. León, D. Mery, F. Pedreschi, and J. León, "Color measurement in $\mathrm{L} * \mathrm{a} * \mathrm{~b} *$ units from RGB digital images," Food Research International, vol. 39, no. 10, pp. 1084-1091, 2006.

[15] A. Said, N. Naeem, S. Siraj et al., "Mechanisms underlying the wound healing and tissue regeneration properties of Chenopodium album," 3 Biotech, vol. 10, no. 10, p. 452, 2020.

[16] M. D. Lane, "Mid-infrared emission spectroscopy of sulfate and sulfate-bearing minerals," American Mineralogist, vol. 92, no. 1, pp. 1-18, 2007.

[17] F. Rosi, A. Daveri, B. Doherty et al., "On the use of overtone and combination bands for the analysis of the $\mathrm{CaSO} 4-\mathrm{H} 2 \mathrm{O}$ system by mid-infrared reflection spectroscopy," Applied Spectroscopy, vol. 64, no. 8, pp. 956-963, 2010.

[18] S. W. K. Sing, "Reporting physisorption data for gas/solid systems with special reference to the determination of surface area and porosity (Recommendations 1984)," Pure \& Applied Chemistry, vol. 57, no. 4, 2013.

[19] Y. Zhang, M. Yuan, B. Jiang, P. Li, and X. Zheng, "Effect of mesoporous structure on $\mathrm{Bi} 3.25 \mathrm{La} 0.75 \mathrm{Ti} 3 \mathrm{O} 12$ powder for humidity sensing properties," Sensors and Actuators B: Chemical, vol. 229, no. 28, pp. 453-460, 2016.

[20] S. U. Qiucheng, Z. Shaohong, C. Peili, L. I. Xinjun, F. U. Juan, and M. A. Longlong, "In situ characterization and analysis on the thermal transformation of boehmite," Chinese Journal of Inorganic Chemistry, vol. 28, no. 11, pp. 2280-2284, 2012.

[21] S. H. Liu, "Effect of calcination time and temperature on three phases of gypsum," Sichuan Building Materials, vol. 40, no. 4, pp. 25-28, 2014.

[22] X. Min, Y. Shi-Long, P. Wei et al., "A novel method for the discrimination of semen arecae and its processed products by using computer vision, electronic nose, and electronic tongue," Evidence-Based Complementary and Alternative Medicine, vol. 2015, Article ID 753942, 10 pages, 2015.

[23] P. L. Arroyo, V. Hatch-Pigott, H. F. Mower, and R. V. Cooney, "Mutagenicity of nitric oxide and its inhibition by antioxidants," Mutation Research Letters, vol. 281, no. 3, p. 193, 1992.

[24] G. Aliev, M. E. Obrenovich, S. Tabrez et al., "Link between cancer and Alzheimer disease via oxidative stress induced by nitric oxide-dependent mitochondrial DNA overproliferation and deletion," Oxidative Medicine and Cellular Longevity, vol. 2013, Article ID 962984, 19 pages, 2013.

[25] Y.-C. Yang, H.-Y. E. Chou, T.-L. Shen, W.-J. Chang, P.-H. Tai, and T.-K. Li, "Topoisomerase II-mediated DNA cleavage and mutagenesis activated by nitric oxide underlie the inflammation-associated tumorigenesis," Antioxidants \& Redox Signaling, vol. 18, no. 10, pp. 1129-1140, 2013.

[26] N. Pallua, P. C. Fuchs, B. Hafemann, U. Völpel, M. Noah, and R. Lütticken, "A new technique for quantitative bacterial assessment on burn wounds by modified dermabrasion," Journal of Hospital Infection, vol. 42, no. 4, p. 329, 1999.

[27] European Wound Management Association (EWMA), Position Document: Identifying Criteria for Wound Infection, MEP Ltd, London, UK, 2005.

[28] L. Danielsen, E. Balslev, G. Döring et al., "Ulcer bed infection," APMIS, vol. 106, no. 7-12, pp. 721-726, 1998.

[29] S. Tejiram and J. W. Shupp, "Infections in burn patients: innovations in infection prevention and treatment," Surgical Infections, vol. 22, 2021.

[30] R. Reid, J. W. Simcock, L. Chisholm, B. Dobbs, and F. A. Frizelle, "Postdischarge clean wound infections: incidence underestimated and risk factors overemphasized," ANZ Journal of Surgery, vol. 72, no. 5, pp. 339-343, 2002.

[31] M. A. Saeed, A. Haque, A. Ali et al., "A profile of drug resistance genes and integrons in E. coli causing surgical wound infections in the Faisalabad region of Pakistan," The Journal of Antibiotics, vol. 62, no. 6, pp. 319-323, 2009.

[32] M. Raviglione, "XDR-TB: entering the post-antibiotic era?" The International Journal of Tuberculosis and Lung Disease: The Official Journal of the International Union Against Tuberculosis and Lung Disease, vol. 10, no. 11, pp. 1185-1187, 2006.

[33] G. D. Mou, "A study on the phase transformation of the bassanites during hydration," Journal of the Chinese Ceramic Society, vol. 4, pp. 532-536, 2002. 
[34] J. H. Zhang, "Purulent wounds should not be smeared with purple potions," Xin Nong Cun, vol. 4, p. 26, 2003.

[35] V. Kanikireddy, K. Varaprasad, T. Jayaramudu, C. Karthikeyan, and R. Sadiku, "Carboxymethyl cellulosebased materials for infection control and wound healing: a review," International Journal of Biological Macromolecules, vol. 164, pp. 963-975, 2020.

[36] Y. Lim, M. A. Levy, and T. M. Bray, "Dietary supplementation of N-acetylcysteine enhances early inflammatory responses during cutaneous wound healing in protein malnourished mice," The Journal of Nutritional Biochemistry, vol. 17, no. 5, pp. 328-336, 2006.

[37] F. Caiado, T. Carvalho, F. Silva et al., "The role of fibrin E on the modulation of endothelial progenitors adhesion, differentiation and angiogenic growth factor production and the promotion of wound healing," Biomaterials, vol. 32, no. 29, pp. 7096-7105, 2011.

[38] T. Xu, Y. J. Xu, X. X. Xu et al., "Effects of gypsum and saimei'an powder on wound healing," Guide of China Medicine, vol. 9, no. 36, pp. 251-252, 2011.

[39] J. Y. Yue and L. Zhang, "Research progress on medicinal gypsum fibrosum," Guangzhou Chemical Industry, vol. 6, no. 44 , pp. $4-6,2016$.

[40] Z. Kopecki, "Development of next-generation antimicrobial hydrogel dressing to combat burn wound infection," Bioscience Reports, vol. 41, 2021.

[41] R. M. Huebinger, D. H. Stones, M. D. S. Santos et al., "Infection following burn injury," Scientific Reports, vol. 6, p. 39341, 2016.

[42] I.-W. Chen and X. H. Wang, "Sintering dense nanocrystalline ceramics without final-stage grain growth," Nature, vol. 404, no. 6774, pp. 168-171, 2000.

[43] S. C. Zheng, Q. Yu, P. Ning et al., "Effect of soluble anhydrite III on hydration process of hemihydrate gypsum," Yunnan Chemical Technology, vol. 43, no. 3, pp. 1-5, 2016.

[44] H. Fan, X. F. Song, Y. X. Xu et al., "Effect of calcination on stabilization of calcium sulfate hemihydrate whiskers," Huadong Ligong Daxue Xuebao, Ziran Kexueban, vol. 45, no. 3, pp. 388-395, 2019.

[45] C. L. YueShan, Q. L. YongzhiWu, and J. Liao, "Hybrid cellulose nanocrystal/alginate/gelatin scaffold with improved mechanical properties and guided wound healing," RSC Advances, vol. 9, 2019.

[46] J. Desousa, M. Tong, J. Wei, L. Chamley, P. Stone, and Q. Chen, "The anti-inflammatory effect of calcium for preventing endothelial cell activation in preeclampsia," Journal of Human Hypertension, vol. 30, 2016.

[47] M. Kuwahara, M. Hatoko, H. Tada, and A. Tanaka, "E-cadherin expression in wound healing of mouse skin," Journal of Cutaneous Pathology, vol. 28, no. 4, pp. 191-199, 2010.

[48] R. N. A. H. Lewis and R. N. Mcelhaney, "Membrane lipid phase transitions and phase organization studied by Fourier transform infrared spectroscopy," Biochimica Et Biophysica Acta, vol. 1828, no. 10, pp. 2347-2358, 2016.

[49] U. Sarac, M. C. Baykul, and Y. Uguz, "Differences observed in the phase structure, grain size-shape, and coercivity Field of electrochemically deposited $\mathrm{Ni}$-Co thin films with different Co contents," Journal of Superconductivity \& Novel Magnetism, vol. 28, no. 10, pp. 1-6, 2015. 